\title{
Recent Trends in the Use of Electrical Neuromodulation in Parkinson's Disease
}

\author{
John-Stuart Brittain ${ }^{1} \cdot$ Hayriye Cagnan ${ }^{2}$
}

Published online: 24 April 2018

(C) The Author(s) 2018

\begin{abstract}
Purpose of Review This review aims to survey recent trends in electrical forms of neuromodulation, with a specific application to Parkinson's disease (PD). Emerging trends are identified, highlighting synergies in state-of-the-art neuromodulation strategies, with directions for future improvements in stimulation efficacy suggested.

Recent Findings Deep brain stimulation remains the most common and effective form of electrical stimulation for the treatment of PD. Evidence suggests that transcranial direct current stimulation (tDCS) most likely impacts the motor symptoms of the disease, with the most prominent results relating to rehabilitation. However, utility is limited due to its weak effects and high variability, with medication state a key confound for efficacy level. Recent innovations in transcranial alternating current stimulation (tACS) offer new areas for investigation.

Summary Our understanding of the mechanistic foundations of electrical current stimulation is advancing and as it does so, trends emerge which steer future clinical trials towards greater efficacy.
\end{abstract}

Keywords Parkinson's disease (PD) · Deep brain stimulation (DBS) · Non-invasive transcranial brain stimulation (NTBS) · Transcranial direct current stimulation (tDCS) · Transcranial alternating current stimulation (tACS) - Direct cortical stimulation

\section{Introduction}

As we pass the bicentennial of James Parkinson's seminal essay on the shaking palsy [1], it is fitting to acknowledge that great strides have been made in our understanding and management of this common neurological condition (2). While many approaches to neuromodulation have been trialled in the treatment of Parkinson's disease (PD) over the years, the most striking is undoubtedly the advent of levodopa as a front-line treatment. The effectiveness of this pharmacological manipulation is remarkable, yet leads to gross motor complications including devastating levodopa-induced dyskinesias (for a review, see [3]). In 1990, it was observed that lesioning the subthalamic nucleus (STN) reversed experimental Parkinsonism [4]. This

This article is part of the Topical Collection on Neuromodulation

John-Stuart Brittain

J.Brittain@bham.ac.uk

1 School of Psychology, University of Birmingham, Edgbaston, Birmingham B15 2TT, UK

2 Institute of Neurology, University College London, London, UK seminal observation was followed by the first trial of deep brain stimulation (DBS) of the STN in 1994 as a treatment for PD [5]. The procedure proved remarkably effective at ablating both the hyper- and hypo-kinetic symptoms of the condition. DBS has since become a common treatment for a range of disorders, with over 100,000 people having undergone implantation worldwide [6]. More recently, transcranial current stimulation (tCS) has re-emerged as a method to non-invasively modulate brain activity and has been trialled in a variety of guises to treat a number of neurological disorders, including PD.

This review will focus on recent trends in the therapeutic application of electrical forms of neuromodulation, with a specific focus on PD. We briefly survey the use of DBS, transcranial direct current stimulation (tDCS) and transcranial alternating current stimulation (tACS) with application to PD, drawing parallels and highlighting differences between these approaches where appropriate. Direct (invasive) cortical stimulation is considered, with perspectives for future applications. Electroconvulsive therapy (ECT) is not directly discussed, but recent reviews and perspectives are available $[7,8]$. Common goals and cross-modal perspectives are given, regarding emerging neuromodulation strategies. The focus on electrical forms of neuromodulation will necessarily omit a 
wealth of recent technological developments and innovations which remain outside the scope of this review; notably MRguided ultrasound $[9,10]$ which has garnered much recent attention for achieving focussed unilateral sub-cortical lesions. For an overview of PD pathology, management and treatment, the reader is directed towards the excellent bicentennial essay of Obeso et al. [2].

While the various forms of stimulation considered here involve the application of electrical currents, the approaches and mechanism of action of DBS, tDCS and tACS are quite distinct and will necessitate tailored strategies in therapeutic or rehabilitative applications. DBS is an invasive neurosurgical procedure where electrical impulses are delivered to precise, stereotactically targeted regions of the brain. tDCS meanwhile involves the application of broad non-invasive transcranial electric fields that modulate cortical excitability in a stimulation polarity dependent fashion [11]. tACS operates principally through sub-threshold electrical modulation of the membrane potential and is hypothesised to induce synchronous states [12]. Yet despite these seemingly disparate approaches, with distinct mechanistic underpinnings, all have been trialled to treat PD and share common traits. One striking similarity is the push towards patient-centric, tailored forms of therapy that include complex field steering and the advent of on-demand and closed-loop strategies. Here, we review recent advances in their respective fields, drawing parallels where appropriate to guide future efforts with the ultimate goal of focussing investigations towards greater clinical utility.

\section{Deep Brain Stimulation}

DBS has proven remarkably effective at alleviating both the hypo- and hyper-kinetic symptoms of PD [13, 14], achieving its therapeutic benefit through the delivery of brief highfrequency (typically in excess of $100 \mathrm{~Hz}$ ) electrical impulses to targeted nuclei through electrodes implanted in sub-cortical regions of the brain that would otherwise remain inaccessible to intervention. Indeed, DBS remains the most prevalent neurosurgical procedure for PD [15], providing effective relief of motor and some non-motor symptoms [16]. However, as previously noted [17], DBS hardware has remained largely static for many years, likely a victim of its own success. Yet a raft of recent innovations stand ready to allow tailored forms of stimulation that may alleviate unwanted side-effects, or even boost the efficacy of stimulation itself. While the exact mechanism of action of DBS still remains unknown, it is now believed that DBS efficacy is rooted in a reversible information lesion that disrupts the expression of pathological neural activity across the motor circuit [18]. In the case of PD, the classic electrophysiological hallmark in the basal ganglia is elevated beta $(13-30 \mathrm{~Hz})$ activity [19], which is suppressed by dopamine and high-frequency DBS [20-24].

\section{Field Shaping}

Although DBS delivers a focal form of stimulation with electrodes entrenched directly in neural tissue, the distribution of the induced electric field is ultimately reliant upon the geometry of the electrode contacts. Traditionally these have been cylindrical, producing an omnidirectional field. However, it has long been known that stimulation of adjacent structures can lead to unwanted side-effects including, most commonly, parasthesias and dysarthria [25]. Recently, the first reports on the clinical efficacy of electric field shaping were published, a technique achieved through the implantation of nextgeneration electrodes that possess either segmented electrodes (typically breaking each cylindrical contact into three radial aspects), or more generic multi-contact designs, permitting the formation of complex stimulation fields.

The first double-blind study into the efficacy of directional DBS electrodes found that the preferred orientation for stimulation significantly improved the therapeutic window over alternate directions, and over omnidirectional stimulation [26] - a result which has since been confirmed [27-32]. The therapeutic window not only takes into account the suppression of motor symptoms but also considers the onset of stimulation-induced side effects. However, the added complexity of programming segmented electrodes emphasises the need for electrophysiological biomarkers to guide contact selection, and perhaps even tune stimulation parameters. Spectral analysis of local field potentials (LFPs) from directional electrodes have already identified localised spectral signatures of beta (and tremor) activity [30, 31, 33] and have directly related stimulation at those contacts to broader therapeutic windows [30, 31].

\section{Adaptive Stimulation}

DBS therefore provides a highly focal, if functionally nonspecific form of neuromodulation. Essentially, stimulation is not reactive to the current brain state [34]; although this does not imply that the effects of stimulation are not brain-state dependent, as elevated levels of beta and tremor-related signals appear more strongly modulated than similar activity occurring at lower intensities, or activity residing in other frequency bands [35]. Despite this, while high-frequency pulse trains are effective in improving the motor (and some nonmotor) aspects of the disease, DBS can produce unwanted behaviours such as impulsivity [36], parasthesias, dysarthria, postural instabilities, and even weight gain [37]. It has been proposed that on-demand stimulation can assist here, where DBS is delivered only when pathophysiological neural activity (linked to disease symptoms) are detected [38]. So far, such trials are limited, but there is evidence to suggest that ondemand stimulation, delivered only when elevated neural activity in the beta-frequency band is present, can improve PD 
motor scores beyond that of continuous high-frequency DBS, while avoiding unwanted side-effects such as speech disturbances [38]. Alternatively, fully closed-loop strategies can be employed that interact with specific neural activity [39・•].

Akin to its high-frequency counterpart, low-frequency stimulation (below $100 \mathrm{~Hz}$ ) can provide therapeutic benefits (in gait, for instance [40]), can be associated with motor degradation [41], and (at very low frequencies) has even been shown to aid cognitive performance in PD [42]. These multifarious findings reassert the dependency between stimulation parameters (such as frequency and intensity) and behavioural outcomes, and further highlight the need for intelligent forms of on-demand closed-loop stimulation that can selectively abate motor symptoms without disrupting (or perhaps even actively normalising) cognitive processes.

Unlike transcranial forms of stimulation, the electrodes employed in DBS directly innervate neural tissue, leading to a form of neuro-stimulation that is strong enough (in most cases at least) to supplant endogenous neural activity. This gives rise to the notion of an information lesion [18]. However, when the frequency (and hence the electrical energy) of stimulation is reduced, signs of brain-state dependence become more noticeable [41]. For instance, the timing of DBS pulses can be adjusted to coincide with the timing of rhythmic tremor production [43]. In Essential Tremor (ET), this leads to both entrainment and phase-specific modulation of tremor severity [44], while in PD the effects appear limited to tremor entrainment, with no significant modulation of tremor severity [43]. Indeed, similar results have been observed when regular pauses are introduced into the stimulation pulse-train, which leads to entrainment [45]. Such stimulation demonstrates that PD tremor is tolerant of intrinsic departures from its median frequency, unlike ET [39••, 46, 47]. Taken with other evidence (e.g. [48-50]), this gives rise to the question of whether PD tremor may in-fact represent a source of filtered noise. These characteristics are important for determining the most effective form of stimulation. While in ET, one could consider targeting specific phases of the tremor cycle [39॰•], in PD a strategy that overcomes the relative tolerance of the tremor generating system, or targets an alternative stimulation site (such as the motor cortex [51]), may be preferable.

\section{Transcranial Direct Current Stimulation}

The field of tDCS has expanded rapidly over the past 20 years $[52,53]$. With this, our understanding of the impact and interaction of tDCS with the brain, especially its pharmacological dependencies, have also developed. Novel electrode configurations have been introduced which promise to deliver stimulation in a more focal manner than ever before.

Despite these advances, recent evidence-based guidelines [54] reveal a chronic lack of sham-controlled randomised controlled tDCS trials in PD, leading to an inability of the authors to provide firm recommendations due to the small number of eligible studies. A lack of replication in protocols and experimental factors, such as the location of stimulating electrodes, further confound the problem. Nevertheless, it was concluded that there was a potential impact of anodal tDCS targeting the motor cortex on gait and motor symptoms from the small number of eligible studies [54]. These supported the notion that combining tDCS with rehabilitative strategies to enhance recovery/motor learning provided the greatest therapeutic promise [54, 55]. A further intriguing development was the finding that anodal TDCS could enhance survival and integration of dopaminergic cells in a rat model of Parkinson's disease [56]. Thus, as in the case of rehabilitation, tDCS may make its major contribution in facilitating primary interventions, in this case cell transplantation therapies.

\section{Pharmacological Action and Interaction}

It has long been recognised that tDCS effects are susceptible to pharmacological state [57]. Indeed, a recent review on the sensitivity of tDCS to medication state emphasised that a wide variety of drugs can reduce, enhance, or even reverse excitability effects [58•]. As such, a more thorough understanding of the underlying brain state, as influenced by medication and stimulation, is needed. This can be aided by proper documentation of medication states during experiments. Of course, physiological variability may also help to explain the broad array of sometimes contradictory evidence present in the tDCS literature (see [59]). Perhaps most importantly in relation to PD is the effect of dopamine, which produced both a dose-dependent, and receptor specific impact on tDCS excitability [60-62], with one study reporting an inverted-U shaped dose-dependent response [61]. Of course, tDCS itself results in neurochemical changes, with anodal tDCS most strongly associated with modulation of GABAergic, and also glutamatergic concentrations $[57,63,64]$. It is likely that these circular dependencies may be responsible for some paradoxical long-term responses to stimulation, including the timedependent reversal of effects. A proper consideration of medication state is therefore a critical element when considering tDCS in trials of PD. Moreover, anatomical differences could influence and confound the stimulation effects both at the site of stimulation and on downstream nuclei. Specifically, it has been shown that axonal orientation could influence whether direct current stimulation results in excitation or inhibition [65]. However, how axonal orientation influences the net stimulation effect in complicated brain structures such as the motor cortex is still debated $[66,67]$. 


\section{Field Shaping}

A further consideration is the shape of the electric field generated by tCS, which dictates the area of electrical innervation in the brain. This is dependent upon the number, and geometric arrangement of stimulating electrodes, and must also take into account the complex conductivity of the brain itself. The electrodes can be positioned in a centre-surround arrangement [68], or be replaced with concentric rings [69]. However, increasing the number of electrodes generally allows greater specificity and multifocal targeting [70,71]. These techniques are yet to be applied for the treatment of PD.

\section{Transcranial Alternating Current Stimulation}

To date, the application of tACS on PD symptomology has remained experimental. Indeed, while the literature on tACS has expanded greatly over the past 15 years (since the reintroduction of the technique [11]), there have been only a handful of papers that have applied tACS in PD patients.

Krause et al. has so far presented the only application of beta-frequency stimulation in a PD cohort [72]. In their shamcontrolled, double-blinded study, the authors assessed the impact of $20 \mathrm{~Hz}$ tACS on cortico-muscular coupling and motor performance in $\mathrm{PD}$ while patients were $O N$ medication, versus a control group. Their aim was not to alleviate symptoms, but rather to assess the impact on isometric contraction and the regularity of finger tapping - since beta-frequencies are associated with bradykinesias in PD [19], and $20 \mathrm{~Hz}$ tACS has previously been shown to slow movement in healthy individuals $[73,74]$. Stimulation attenuated beta-band cortico-muscular coupling during isometric contraction, and reduced amplitude variability during finger tapping in the PD group, but had no discernible impact on the control group. They conclude that PD may in fact be more responsive to tACS due to the altered pathophysiological brain state.

Taking a different approach, Shill et al. [75] applied highfrequency $(77.5 \mathrm{~Hz})$, high-amplitude $(15 \mathrm{~mA})$ stimulation as a prospective, offline treatment, delivering stimulation over 45 min per session for 10 days. They concluded that stimulation bore no significant benefits over placebo in UPDRS (parts I-III), anxiety, depression or sleepiness scales over the course of the experiment. Despite this, gamma frequency stimulation has been shown to speed motor responses in healthy individuals [76], and so could be further trialled as a treatment for bradykinesia.

\section{Adaptive Stimulation}

Due to the lack of experimental data relating to open-loop stimulation, no on-demand protocols have so far been trialled. However, closed-loop stimulation has been attempted focussing on the symptom of resting tremor. Brittain et al. [51] demonstrated that tACS could partially entrain and amplitude modulate peripheral tremor as recorded by accelerometery. In this study, the peripheral movement itself was employed as a proxy for central brain activity [77], using closed-loop control to align the stimulation waveform with on-going movements in real-time. It was demonstrated that sustained closed-loop stimulation led to an order-of-magnitude increase in the effect-size of suppression of the pathological tremor over the open-loop configuration, without impacting gross motor performance. This study demonstrates the importance of temporally guided stimulation paradigms [78], especially in modalities where the strength of stimulation is weak compared to endogenous/aberrant brain activity (i.e. see $[12,79]$ ).

The influence of tACS over the cerebellum has also been assessed in relation to PD tremor. In a cohort of mixed PD and ET patients, tACS applied between ipsilateral cerebellum and extracephalic contralateral shoulder was shown to entrain those tremors that were pliant to oscillate within a limited range of frequencies [46]. In the same study, it was shown that PD tremor displayed this pliancy to a greater extent than patients with ET, suggesting a greater tendency to entrainment. However, it should be noted that a direct comparison between PD and ET patients was not significant, possibly due to the small sample of participants in this study.

\section{Pharmacological Action and Interaction}

When discussing tACS, the emphasis is usually on temporal alignment to maximise the impact of sub-threshold modulations in the membrane potential [78]. However, there is growing evidence that tACS is also responsible for changes in neurotransmitter concentrations and cortical plasticity. For instance, stimulation at gamma-frequencies ( $75 \mathrm{~Hz}$ in this case) has been shown to drive local $\mathrm{GABA}_{\mathrm{A}}$ inhibition [80]. In addition, Guerra et al. [81] demonstrated the abolition of cholinergic short-latency afferent inhibition (SAI) during tACS at $20 \mathrm{~Hz}$ (separate from the phase-dependent effects that were also observed). Clearly, we must also consider the impact of alternating currents on neurochemical processes in our experimental designs, even if only to monitor and mitigate the reactive impact that these changes might cause to our neuromodulation efforts.

\section{Field Shaping}

In both DBS and tCS, complex field shaping is made possible by developments in hardware. In tACS however, high-density electrode configurations offer the possibility to deliver not only more focal forms of stimulation, but also novel stimulation protocols. For instance, the reinforcement or disruption of synchronised neural rhythms 
between brain regions through in- and out-of-phase stimulation [82-85]. One downside has been the induction of steeper current gradients focussed over a smaller area that can lead to an exacerbation of sensory side effects (a particular problem when time-varying currents are employed). Indeed, perhaps the limiting factor in the delivery of tCS so far has been discomfort arising from cutaneous nociception [86].

Recently, there have been new developments in the delivery of tCS that may overcome some of these unwanted sensory side effects and, in so doing, permit the delivery of higher-intensity stimulation. The first is the suggested use of topical anaesthetics to numb sensation (as described in [86]). The second is the use of highfrequency amplitude-modulated stimulation, which delivers current beyond the response range of cutaneous receptors. This approach offers the additional benefit of reducing (or removing) stimulation artefact from the frequency range of interest, permitting simultaneous MEG or even EEG recordings to be made. The approach has been trialled with some success [87], although the knock-on impact of amplitude-modulated tACS is that the neural response to such beat frequencies is unclear; indeed, it may be that substantially stronger currents are required to induce neural modulation after signal loss due to the presumed (partial) demodulation of the stimulus waveform at the neuronal level. This is compounded by our lack of understanding about the mechanism through which demodulation occurs [88], although it possibly reflects nonlinearities in the cell membrane response [78, 87]. In support of this, triangular stimulation waveforms have been reported to modulate brain activity perhaps more effectively than sine-waves [89]. One further development is the advent of temporal interference stimulation, which applies two separate high-frequency ( $\mathrm{kHz}$ range) stimulation waveforms simultaneously. At their intersection, an amplitude-modulated waveform is produced [90••]. This elegant solution permits considerable flexibility in field steering, and raises the exciting prospect of selectively targeting deeper brain regions. Although the technique has only been demonstrated in mice at this point, translation into human studies appears immediately feasible, although it remains to be seen whether such forms of stimulation can induce sufficient modulation in a reliable, controlled manner to offer real therapeutic prospects. One drawback of high-density arrangements is that as the focality of stimulation improves, the need for accurate placement of electrodes, and incorporation of individualised head models to provide reliable current steering becomes a necessity, significantly complicating the approach. Nevertheless, such advancements provide the opportunity to develop these techniques as either offline therapies, pre-surgical screening tools, or even as a precursor to a fully implanted epidural stimulation system.

\section{Direct Cortical Stimulation}

Direct stimulation of the motor cortex in the treatment of PD has been trialled with varying success over the years [91]. Stimulation can be subdural, but minimally invasive epidural methods seem to be preferred due to reduced surgical risks [91]. Efficacy has been variable, but is generally considered less efficacious than DBS [92]. This is potentially due to the dependency between stimulation site (cortical or sub-cortical) and behavioural effects, and confounded by limits on stimulation intensity in order to prevent seizure onset. Stimulation efficacy could be improved by determining the optimum stimulation site according to patient specific brain connectivity in order to reveal the "sweet spot" for modulating downstream nuclei in the motor circuit [93]. This type of approaches could be important for treating disorders like PD that arise from complex network interactions. DBS is associated with greater surgical risks than epidural methods, and is not effective in all patients, especially those who prove nonresponsive to dopaminergic medication [94]. Indeed, direct cortical stimulation may be a treatment option in patients who prove unresponsive to, or are otherwise contraindicative for DBS, demonstrating improvements in gait and axial symptoms [92]. Meanwhile, noninvasive forms of stimulation such as tACS has shown some promise in closed-loop forms of stimulation, but such closed-loop strategies require chronic applications, which are not currently realisable in its present form.

Could direct cortical stimulation provide a harmonious solution to some of these problems and offer a hybrid alternative therapy? Direct cortical stimulation possesses many attributes that make it a desirable intervention. It can be delivered chronically, is minimally invasive offering reduced surgical risks, and provides focal stimulation of targeted cortical regions. Does direct cortical stimulation therefore offer a convenient minimally invasive surgical option for the implementation of a chronic form of closed-loop tACS? Techniques such as temporal interference could be adapted to chronic applications across multiple electrodes [90••], offering deep epidural stimulation and targeting of midline structures. Such stimulus delivery could offer advantages over existing direct cortical stimulation, including the potential for improved efficacy. Compared to tACS, direct cortical stimulation can deliver stronger and focussed current densities. Compared with pulsatile stimulation, sine-wave modulation may reduce seizure risk due to the less acerbic nature of the stimulus.

\section{Common Goals and Future Directions}

There are clear parallels to be drawn for the next-generation of electrical neuromodulation techniques. There is a 
tendency to seek greater anatomical and functional specificity. All forms have been associated with neuroplastic effects and pharmacological dependencies, and an emerging recognition that underlying brain state is an important consideration in effective neuromodulation. But these factors also overlap. Greater anatomical specificity goes hand-in-hand with the identification and preferential targeting of biological signatures of pathology, which in turn drives on-demand and closed-loop strategies. The pharmacological impact of stimulation, either by direct or indirect methods, will affect the efficacy of subsequent periods of stimulation. tDCS presently appears most suitable as an adjunct method in priming and rehabilitative training.

\section{Conclusions}

Electrical neuromodulation remains a promising and powerful tool to interrogate neural circuits, with recent developments favouring greater anatomical and functional specificity. Techniques such as DBS are well established and have received a recent resurgence in innovation that offers new therapeutic options. Meanwhile, tCS remains a technique in its infancy, where the mechanisms of action remain unclear. As our understanding of these techniques improves, our capacity to trial novel therapeutic interventions also improves. While the surveyed approaches have shown early promise in increasing the potency and selectivity of stimulation, further clinical trials are clearly required. Continued technological developments offer the opportunity of new and innovative approaches to probe PD pathophysiology and abate the symptoms of PD.

Funding Information This research was funded by the Medical Research Council (MR/N003446/1, MR/M014762/1).

\section{Compliance with Ethical Standards}

Conflict of Interest Dr. Brittain has a patent GB1700767.5 (Method and System For Determining Tremor Status) pending to Oxford University Innovation Limited.

Dr. Cagnan has nothing to disclose.

Human and Animal Rights and Informed Consent This article does not contain any studies with human or animal subjects performed by any of the authors.

Open Access This article is distributed under the terms of the Creative Commons Attribution 4.0 International License (http:// creativecommons.org/licenses/by/4.0/), which permits unrestricted use, distribution, and reproduction in any medium, provided you give appropriate credit to the original author(s) and the source, provide a link to the Creative Commons license, and indicate if changes were made.

\section{References}

Papers of particular interest, published recently, have been highlighted as:

- Of importance

- Of major importance

1. Parkinson J. An essay on the shaking palsy. London: Whittingham and Rowland Sherwood, Neely and Jones; 1817.

2. Obeso JA, Stamelou M, Goetz CG, Poewe W, Lang AE, Weintraub $\mathrm{D}$, et al. Past, present, and future of Parkinson's disease: a special essay on the 200th anniversary of the shaking palsy. Mov Disord. 2017;32(9):1264-310.

3. Pandey S, Srivanitchapoom P. Levodopa-induced dyskinesia: clinical features, pathophysiology, and medical management. Ann Indian Acad Neurol. 2017;20(3):190-8.

4. Bergman H, Wichmann T, DeLong MR. Reversal of experimental parkinsonism by lesions of the subthalamic nucleus. Science. 1990;249(4975):1436-8.

5. Benabid AL, Pollak P, Gross C, Hoffmann D, Benazzouz A, Gao $\mathrm{DM}$, et al. Acute and long-term effects of subthalamic nucleus stimulation in Parkinson's disease. Stereotact Funct Neurosurg. 1994;62(1-4):76-84.

6. Sugiyama K, Nozaki T, Asakawa T, Koizumi S, Saitoh O, Namba $\mathrm{H}$. The present indication and future of deep brain stimulation. Neurol Med Chir (Tokyo). 2015 May;55(5):416-21.

7. Narang P, Glowacki A, Lippmann S. Electroconvulsive therapy intervention for Parkinson's disease. Innov Clin Neurosci. 2015;12(9-10):25-8.

8. Cumper SK, Ahle GM, Liebman LS, Kellner CH. Electroconvulsive therapy (ECT) in Parkinson's disease: ECS and dopamine enhancement. J ECT. 2014;30(2):122-4.

9. Weintraub D, Elias WJ. The emerging role of transcranial magnetic resonance imaging-guided focused ultrasound in functional neurosurgery. Mov Disord Off J Mov Disord Soc. 2017;32(1):20-7.

10. Krishna V, Sammartino F, Rezai A. A review of the current therapies, challenges, and future directions of transcranial focused ultrasound technology: advances in diagnosis and treatment. JAMA Neurol 2017

11. Woods AJ, Antal A, Bikson M, Boggio PS, Brunoni AR, Celnik P, et al. A technical guide to tDCS, and related non-invasive brain stimulation tools. Clin Neurophysiol. 2016;127(2):1031-48.

12. Ali MM, Sellers KK, Fröhlich F. Transcranial alternating current stimulation modulates large-scale cortical network activity by network resonance. J Neurosci. 2013;33(27):11262-75.

13. Ponce FA, Lozano AM. Chapter 16 - Deep brain stimulation: state of the art and novel stimulation targets. In: Björklund A, Cenci MA, editors. Progress in brain research [Internet]. Elsevier; 2010 [cited 2017 Dec 15]. p. 311-24. (Recent Advances in Parkinson'S Disease; vol. 184). Available from: http://www.sciencedirect.com/ science/article/pii/S0079612310840166

14. Shukla AW, Okun MS. State of the art for deep brain stimulation therapy in movement disorders: a clinical and technological perspective. IEEE Rev Biomed Eng. 2016;9:219-33.

15. Lozano CS, Tam J, Lozano AM. The changing landscape of surgery for Parkinson's disease. Mov Disord Off J Mov Disord Soc. $2017 ; 30$

16. Kurtis MM, Rajah T, Delgado LF, Dafsari HS. The effect of deep brain stimulation on the non-motor symptoms of Parkinson's disease: a critical review of the current evidence. NPJ Park Dis. 2017;3:16024.

17. Hariz M. Deep brain stimulation: new techniques. Parkinsonism Relat Disord. 2014;20(Suppl 1):S192-6. 
18. Grill WM, Snyder AN, Miocinovic S. Deep brain stimulation creates an informational lesion of the stimulated nucleus. Neuroreport. 2004;15(7):1137-40.

19. Brittain J-S, Brown P. Oscillations and the basal ganglia: motor control and beyond. NeuroImage. 2014;85(Pt 2):637-47.

20. Eusebio A, Thevathasan W, Gaynor LD, Pogosyan A, Bye E, Foltynie T, et al. Deep brain stimulation can suppress pathological synchronisation in parkinsonian patients. J Neurol Neurosurg Psychiatry. 2011;82(5):569-73.

21. Kühn AA, Kupsch A, Schneider G-H, Brown P. Reduction in subthalamic $8-35 \mathrm{~Hz}$ oscillatory activity correlates with clinical improvement in Parkinson's disease. Eur J Neurosci. 2006;23(7): 1956-60.

22. Kühn AA, Tsui A, Aziz T, Ray N, Brücke C, Kupsch A, et al. Pathological synchronisation in the subthalamic nucleus of patients with Parkinson's disease relates to both bradykinesia and rigidity. Exp Neurol. 2009;215(2):380-7.

23. Ray NJ, Jenkinson N, Wang S, Holland P, Brittain JS, Joint C, et al. Local field potential beta activity in the subthalamic nucleus of patients with Parkinson's disease is associated with improvements in bradykinesia after dopamine and deep brain stimulation. Exp Neurol. 2008;213(1):108-13.

24. Weinberger M, Mahant N, Hutchison WD, Lozano AM, Moro E, Hodaie $\mathrm{M}$, et al. Beta oscillatory activity in the subthalamic nucleus and its relation to dopaminergic response in Parkinson's disease. J Neurophysiol. 2006;96(6):3248-56.

25. Fytagoridis A, Åström M, Wårdell K, Blomstedt P. Stimulationinduced side effects in the posterior subthalamic area: distribution, characteristics and visualization. Clin Neurol Neurosurg. 2013;115(1):65-71.

26. Pollo C, Kaelin-Lang A, Oertel MF, Stieglitz L, Taub E, Fuhr P, et al. Directional deep brain stimulation: an intraoperative doubleblind pilot study. Brain J Neurol. 2014;137(Pt 7):2015-26.

27. Dembek TA, Reker P, Visser-Vandewalle V, Wirths J, Treuer H, Klehr M, et al. Directional DBS increases side-effect thresholds-a prospective, double-blind trial. Mov Disord Off J Mov Disord Soc. 2017;32(10):1380-8.

28. Reker P, Dembek TA, Becker J, Visser-Vandewalle V, Timmermann L. Directional deep brain stimulation: a case of avoiding dysarthria with bipolar directional current steering. Parkinsonism Relat Disord. 2016;31:156-8.

29. Steigerwald F, Müller L, Johannes S, Matthies C, Volkmann J. Directional deep brain stimulation of the subthalamic nucleus: a pilot study using a novel neurostimulation device. Mov Disord Off J Mov Disord Soc. 2016;31(8):1240-3.

30. Fernández-García C, Foffani G, Dileone M, Catalán-Alonso MJ, González-Hidalgo M, Barcía JA, et al. Directional local field potential recordings for symptom-specific optimization of deep brain stimulation. Mov Disord Off J Mov Disord Soc. 2017;32(4):626-8.

31. Tinkhauser G, Pogosyan A, Debove I, Nowacki A, Shah SA, Seidel K, et al. Directional local field potentials: a tool to optimize deep brain stimulation. Mov Disord Off J Mov Disord Soc. 2017 18;

32. Timmermann L, Jain R, Chen L, Maarouf M, Barbe MT, Allert N, et al. Multiple-source current steering in subthalamic nucleus deep brain stimulation for Parkinson's disease (the VANTAGE study): a non-randomised, prospective, multicentre, open-label study. Lancet Neurol. 2015;14(7):693-701.

33. Bour LJ, Lourens MAJ, Verhagen R, de Bie RMA, van den Munckhof P, Schuurman PR, et al. Directional recording of subthalamic spectral power densities in Parkinson's disease and the effect of steering deep brain stimulation. Brain Stimulat. 2015;8(4):730-41.

34. Brittain J-S, Sharott A, Brown P. The highs and lows of beta activity in cortico-basal ganglia loops. Eur J Neurosci. 2014;39(11):1951-9.

35. Eusebio A, Cagnan H, Brown P. Does suppression of oscillatory synchronisation mediate some of the therapeutic effects of DBS in patients with Parkinson's disease? Front Integr Neurosci [Internet].
2012 [cited 2018 Feb 15];6. Available from: https://doi.org/10. 3389/fnint.2012.00047/full

36. Hälbig TD, Tse W, Frisina PG, Baker BR, Hollander E, Shapiro H, et al. Subthalamic deep brain stimulation and impulse control in Parkinson's disease. Eur J Neurol. 2009;16(4):493-7.

37. Guehl D, Cuny E, Benazzouz A, Rougier A, Tison F, Machado $\mathrm{S}$, et al. Side-effects of subthalamic stimulation in Parkinson's disease: clinical evolution and predictive factors. Eur J Neurol. 2006;13(9):963-71.

38. Little S, Tripoliti E, Beudel M, Pogosyan A, Cagnan H, Herz D, et al. Adaptive deep brain stimulation for Parkinson's disease demonstrates reduced speech side effects compared to conventional stimulation in the acute setting. J Neurol Neurosurg Psychiatry. 2016;87(12):1388-9.

39.• Cagnan H, Pedrosa D, Little S, Pogosyan A, Cheeran B, Aziz T, et al. Stimulating at the right time: phase-specific deep brain stimulation. Brain J Neurol. 2017;140(1):132-45. First demonstration in humans of the effectiveness of phase-specific closed-loop stimulation during DBS

40. Baizabal-Carvallo JF, Alonso-Juarez M. Low-frequency deep brain stimulation for movement disorders. Parkinsonism Relat Disord. 2016;31(Supplement C):14-22.

41. Eusebio A, Chen CC, Lu CS, Lee ST, Tsai CH, Limousin P, et al. Effects of low-frequency stimulation of the subthalamic nucleus on movement in Parkinson's disease. Exp Neurol. 2008;209(1):125-30.

42. Kelley R, Flouty O, Emmons EB, Kim Y, Kingyon J, Wessel JR, et al. A human prefrontal-subthalamic circuit for cognitive control. Brain [Internet]. [cited 2017 Dec 14]; Available from: https://doi. org/10.1093/brain/awx300/4665976

43. Cagnan H, Little S, Foltynie T, Limousin P, Zrinzo L, Hariz M, et al. The nature of tremor circuits in parkinsonian and essential tremor. Brain J Neurol. 2014;137(Pt 12):3223-34.

44. Cagnan H, Brittain J-S, Little S, Foltynie T, Limousin P, Zrinzo L, et al. Phase dependent modulation of tremor amplitude in essential tremor through thalamic stimulation. Brain J Neurol. 2013;136(Pt 10):3062-75.

45. Swan BD, Brocker DT, Hilliard JD, Tatter SB, Gross RE, Turner DA, et al. Short pauses in thalamic deep brain stimulation promote tremor and neuronal bursting. Clin Neurophysiol. 2016;127(2):1551-9.

46. Brittain J-S, Cagnan H, Mehta AR, Saifee TA, Edwards MJ, Brown P. Distinguishing the central drive to tremor in Parkinson's disease and essential tremor. J Neurosci. 2015;35(2):795-806.

47. di Biase L, Brittain J-S, Shah SA, Pedrosa DJ, Cagnan H, Mathy A, et al. Tremor stability index: a new tool for differential diagnosis in tremor syndromes. Brain J Neurol. 2017;140(7):1977-86.

48. Duval C, Daneault J-F, Hutchison WD, Sadikot AF. A brain network model explaining tremor in Parkinson's disease. Neurobiol Dis. 2016;85(Supplement C):49-59.

49. Dirkx MF,den Ouden HE, Aarts E, Timmer MHM, Bloem BR, et al. Dopamine controls Parkinson's tremor by inhibiting the cerebellar thalamus. Brain 2017;140(3):721-734.

50. Algarni M, Fasano A. The overlap between essential tremor and Parkinson disease. Parkinsonism Relat Disord. 2018;46(Suppl 1):S101-4.

51. Brittain J-S, Probert-Smith P, Aziz TZ, Brown P. Tremor suppression by rhythmic transcranial current stimulation. Curr Biol CB. 2013;23(5):436-40.

52. Priori A, Berardelli A, Rona S, Accornero N, Manfredi M. Polarization of the human motor cortex through the scalp. Neuroreport. 1998;9(10):2257-60.

53. Nitsche MA, Paulus W. Excitability changes induced in the human motor cortex by weak transcranial direct current stimulation. J Physiol. 2000;527(3):633-9.

54. Lefaucheur J-P, Antal A, Ayache SS, Benninger DH, Brunelin J, Cogiamanian F, et al. Evidence-based guidelines on the therapeutic 
use of transcranial direct current stimulation (tDCS). Clin Neurophysiol Off J Int Fed Clin Neurophysiol. 2017;128(1):56-92.

55. Benninger DH, Hallett M. Non-invasive brain stimulation for Parkinson's disease: current concepts and outlook 2015. NeuroRehabilitation. 2015;37(1):11-24.

56. Winkler C, Reis J, Hoffmann N, Gellner A-K, Münkel C, Curado $\mathrm{MR}$, et al. Anodal transcranial direct current stimulation enhances survival and integration of dopaminergic cell transplants in a rat Parkinson model. eNeuro. 2017;4(5):ENEURO.0063-17.2017.

57. Stagg CJ, Nitsche MA. Physiological basis of transcranial direct current stimulation. Neurosci Rev J Bringing Neurobiol Neurol Psychiatry. 2011;17(1):37-53.

58. McLaren ME, Nissim NR, Woods AJ. The effects of medication use in transcranial direct current stimulation: a brief review. Brain Stimulat. 2017. Provides an important contemporary review of evidence concerning the effects of pharmacology on tDCSinduced excitability.

59. Li LM, Uehara K, Hanakawa T. The contribution of interindividual factors to variability of response in transcranial direct current stimulation studies. Front Cell Neurosci. 2015;9:181

60. Nitsche MA, Lampe C, Antal A, Liebetanz D, Lang N, Tergau F, et al. Dopaminergic modulation of long-lasting direct currentinduced cortical excitability changes in the human motor cortex. Eur J Neurosci. 2006;23(6):1651-7.

61. Monte-Silva K, Liebetanz D, Grundey J, Paulus W, Nitsche MA. Dosage-dependent non-linear effect of 1-dopa on human motor cortex plasticity. J Physiol. 2010;588(18):3415-24.

62. Fresnoza S, Stiksrud E, Klinker F, Liebetanz D, Paulus W, Kuo M-F, et al. Dosage-dependent effect of dopamine D2 receptor activation on motor cortex plasticity in humans. J Neurosci. 2014;34(32):10701-9.

63. Nitsche MA, Liebetanz D, Schlitterlau A, Henschke U, Fricke K, Frommann K, et al. GABAergic modulation of DC stimulationinduced motor cortex excitability shifts in humans. Eur J Neurosci. 2004;19(10):2720-6.

64. Kim S, Stephenson MC, Morris PG, Jackson SR. tDCS-induced alterations in GABA concentration within primary motor cortex predict motor learning and motor memory: a $7 \mathrm{~T}$ magnetic resonance spectroscopy study. NeuroImage. 2014;99(100):237-43.

65. Kabakov AY, Muller PA, Pascual-Leone A, Jensen FE, Rotenberg A. Contribution of axonal orientation to pathway-dependent modulation of excitatory transmission by direct current stimulation in isolated rat hippocampus. J Neurophysiol. 2012;107(7):1881-9.

66. Radman T, Ramos RL, Brumberg JC, Bikson M. Role of cortical cell type and morphology in subthreshold and suprathreshold uniform electric field stimulation in vitro. Brain Stimulat. 2009;2(4): 215-28. 228.e1-3

67. Rahman A, Reato D, Arlotti M, Gasca F, Datta A, Parra LC, et al. Cellular effects of acute direct current stimulation: somatic and synaptic terminal effects. J Physiol. 2013;591(10):2563-78.

68. Datta A, Bansal V, Diaz J, Patel J, Reato D, Bikson M. Gyri-precise head model of transcranial DC stimulation: improved spatial focality using a ring electrode versus conventional rectangular pad. Brain Stimulat. 2009;2(4):201-7.

69. Gbadeyan O, Steinhauser M, McMahon K, Meinzer M. Safety, tolerability, blinding efficacy and behavioural effects of a novel MRI-compatible, high-definition tDCS set-up. Brain Stimul Basic Transl Clin Res Neuromodulation. 2016;9(4):545-52.

70. Dannhauer M, Brooks D, Tucker D, MacLeod R. A Pipeline for the simulation of transcranial direct current stimulation for realistic human head models using SCIRun/BioMesh3D. In: 2012 Annual International Conference of the IEEE Engineering in Medicine and Biology Society 2012. p. 5486-9.

71. Ruffini G, Fox MD, Ripolles O, Miranda PC, Pascual-Leone A. Optimization of multifocal transcranial current stimulation for weighted cortical pattern targeting from realistic modeling of electric fields. NeuroImage. 2014;89(Supplement C):216-25.

72. Krause V, Wach C, Südmeyer M, Ferrea S, Schnitzler A, Pollok B. Cortico-muscular coupling and motor performance are modulated by $20 \mathrm{~Hz}$ transcranial alternating current stimulation (tACS) in Parkinson's disease. Front Hum Neurosci. 2013;7:928

73. Joundi RA, Jenkinson N, Brittain J-S, Aziz TZ, Brown P. Driving oscillatory activity in the human cortex enhances motor performance. Curr Biol CB. 2012;22(5):403-7.

74. Pogosyan A, Gaynor LD, Eusebio A, Brown P. Boosting cortical activity at beta-band frequencies slows movement in humans. Curr Biol CB. 2009;19(19):1637-41.

75. Shill HA, Obradov S, Katsnelson Y, Pizinger R. A randomized, double-blind trial of transcranial electrostimulation in early Parkinson's disease. Mov Disord Off J Mov Disord Soc. 2011;26(8):1477-80.

76. Joundi RA, Brittain J-S, Green AL, Aziz TZ, Brown P, Jenkinson N. Persistent suppression of subthalamic beta-band activity during rhythmic finger tapping in Parkinson's disease. Clin Neurophysiol Off J Int Fed Clin Neurophysiol. 2013;124(3):565-73.

77. Timmermann L, Gross J, Dirks M, Volkmann J, Freund H-J, Schnitzler A. The cerebral oscillatory network of parkinsonian resting tremor. Brain. 2003;126(1):199-212.

78. Thut G, Bergmann TO, Fröhlich F, Soekadar SR, Brittain J-S, Valero-Cabré A, et al. Guiding transcranial brain stimulation by EEG/MEG to interact with ongoing brain activity and associated functions: a position paper. Clin Neurophysiol Off J Int Fed Clin Neurophysiol. 2017;128(5):843-57.

79. Fröhlich F, McCormick DA. Endogenous electric fields may guide neocortical network activity. Neuron. 2010;67(1):129-43.

80. Nowak M, Hinson E, van Ede F, Pogosyan A, Guerra A, Quinn A, et al. Driving human motor cortical oscillations leads to behaviorally relevant changes in local GABAA inhibition: a tACS-TMS study. J Neurosci. 2017;37(17):4481-92.

81. Guerra A, Pogosyan A, Nowak M, Tan H, Ferreri F, Di Lazzaro V, et al. Phase dependency of the human primary motor cortex and cholinergic inhibition cancelation during beta tACS. Cereb Cortex N Y NY. 2016;26(10):3977-90.

82. Helfrich RF, Knepper H, Nolte G, Strüber D, Rach S, Herrmann $\mathrm{CS}$, et al. Selective modulation of interhemispheric functional connectivity by HD-tACS shapes perception. PLoS Biol. 2014;12(12): e1002031.

83. Strüber D, Rach S, Trautmann-Lengsfeld SA, Engel AK, Herrmann CS. Antiphasic $40 \mathrm{~Hz}$ oscillatory current stimulation affects bistable motion perception. Brain Topogr. 2014;27(1):158-71.

84. Saturnino GB, Madsen KH, Siebner HR, Thielscher A. How to target inter-regional phase synchronization with dual-site transcranial alternating current stimulation. NeuroImage. 2017;163:68-80.

85. Bächinger M, Zerbi V, Moisa M, Polania R, Liu Q, Mantini D, et al. Concurrent tACS-fMRI reveals causal influence of power synchronized neural activity on resting state fMRI connectivity. J Neurosci. 2017;37(18):4766-77.

86. Khatoun A, Asamoah B, Laughlin MM. Simultaneously excitatory and inhibitory effects of transcranial alternating current stimulation revealed using selective pulse-train stimulation in the rat motor cortex. J Neurosci. 2017:1390-17.

87. Witkowski M, Garcia-Cossio E, Chander BS, Braun C, Birbaumer $\mathrm{N}$, Robinson SE, et al. Mapping entrained brain oscillations during transcranial alternating current stimulation (tACS). NeuroImage. 2016;140:89-98.

88. Dmochowski J, Bikson M. Noninvasive neuromodulation goes deep. Cell. 2017;169(6):977-8.

89. Dowsett J, Herrmann CS. Transcranial alternating current stimulation with sawtooth waves: simultaneous stimulation and EEG 
recording. Front Hum Neurosci [Internet]. 2016 Mar 29 [cited 2017 Dec 14];10. Available from: https://www.ncbi.nlm.nih.gov/pmc/ articles/PMC4809871/

90.• Grossman N, Bono D, Dedic N, Kodandaramaiah SB, Rudenko A, Suk H-J, et al. Noninvasive deep brain stimulation via temporally interfering electric fields. Cell. 2017;169(6):10291041.e16. Introduced the temporal interference technique which enables non-invasive delivery of alternating current stimulation to deep regions of the brain.

91. Lavano A, Guzzi G, DE Rose M, Romano M, Della Torre A, Vescio $\mathrm{G}$, et al. Minimally invasive motor cortex stimulation for Parkinson's disease. J Neurosurg Sci. 2017;61(1):77-87.
92. De Rose M, Guzzi G, Bosco D, Romano M, Lavano SM, Plastino $\mathrm{M}$, et al. Motor cortex stimulation in Parkinson's disease [Internet]. Neurology Research International. 2012 [cited 2017 Dec 15]. Available from: https:/www.hindawi.com/journals/nri/2012/ 502096/

93. Horn A, Neumann W-J, Degen K, Schneider G-H, Kühn AA. Toward an electrophysiological 'sweet spot' for deep brain stimulation in the subthalamic nucleus. Hum Brain Mapp 2017

94. Suarez-Cedeno G, Suescun J, Schiess MC. Earlier intervention with deep brain stimulation for Parkinson's disease. Park Dis. 2017;2017:9358153. 